\begin{tabular}{|c|c|}
\hline Title: & $\begin{array}{l}\text { Sensor-less Control of a PMSM for Safety Critical Applications Using Hysteresis Current } \\
\text { Control in Case of an Encoder Failure }\end{array}$ \\
\hline Authors: & Felix Hoffmann, Marc Veigel, Martin Doppelbauer \\
\hline Institute: & $\begin{array}{l}\text { Karlsruhe Institute of Technology (KIT) } \\
\text { Institute of Electrical Engineering (ETI) }\end{array}$ \\
\hline Type: & Conference Proceedings \\
\hline Published at: & $\begin{array}{l}2018 \text { IEEE International Conference on Power Electronics, Drives and Energy Systems } \\
\text { (PEDES) } \\
\text { Publisher: IEEE } \\
\text { Year: } 2019 \\
\text { ISBN: } 978-1-5386-9316-2 \\
\text { Pages: } 1-6\end{array}$ \\
\hline Hyperlinks: & https://ieeexplore.ieee.org/document/9270718 \\
\hline
\end{tabular}

(c) 2019 IEEE. Personal use of this material is permitted. Permission from IEEE must be obtained for all other uses, in any current or future media, including reprinting/republishing this material for advertising or promotional purposes, creating new collective works, for resale or redistribution to servers or lists, or reuse of any copyrighted component of this work in other works. 


\title{
Sensor-less Control of a PMSM for Safety Critical Applications Using Hysteresis Current Control in Case of an Encoder Failure
}

\author{
Felix Hoffmann \\ Marc Veigel \\ Martin Doppelbauer \\ Institute of Electrical Engineering (ETI) Institute of Electrical Engineering (ETI) Institute of Electrical Engineering (ETI) \\ Karlsruhe Institute of Technology (KIT) Karlsruhe Institute of Technology (KIT) Karlsruhe Institute of Technology (KIT) \\ Karlsruhe, Germany \\ felix.hoffmann@kit.edu \\ Karlsruhe, Germany \\ Karlsruhe, Germany \\ marc.veigel@kit.edu \\ martin.doppelbauer@kit.edu
}

\begin{abstract}
Encoders are one of the critical parts in an electric drive system. In safety critical applications like an air plane a redundant and robust sensor-less controller with an approval in aviation is required. This paper presents a hysteresis current controller, which is implemented on a FPGA. We simulated the switching action and the controller dynamics and measured it on a test bench. We describe the transients excited by the switching action analytically. Although transients are excited at the switching moment, a stable operation of the machine is ensured. The results of simulation and measurement of the switching action show a maximal deviation of $6 \%$ in the stator current amplitude. The excited transients describe a sinusoidal shape for the rotor speed. The analytical solution of the oscillation amplitude deviates from the measured results by a maximum of $14 \%$. The oscillation frequency is $24 \%$ up to $35 \%$ smaller, depending on the operating point. The differences are due to the assumption of phase currents with a constant amplitude. It is shown that the dq-current components follow the constant torque hyperbola, if the current reference amplitude changes. In case of a load torque change they will move on the constant stator current circle and turning clockwise for a load torque decrease and counter clockwise for an increase. Due to the working principle of the controller, the current distortion is significant and is measured to $29 \%$ in a defined operating point. The measurement results validate the simulation results. The implemented hysteresis current controller can be used to improve the redundancy of a control structure.
\end{abstract}

Index Terms - sensor-less control, permanent magnet synchronous machine, hysteresis control, encoder failure, safety critical application

\section{INTRODUCTION}

Safety critical applications like all electric aircraft [1] are gaining a lot of attention nowadays. In this context sensorbased control schemes like [2]-[5] can not maintain a safe operation in case of an encoder failure. For safety cirital applications it is not an option to shut down the electrical machine in this case. A safe operation of the machine must be ensured, to minimize the risk of further damage. The required control method does not need to fulfill any efficiency or dynamic requirement. The main purpose of the control structure is to maintain a safe operation of the aircraft. Neces- sary redundancies for electric aircraft applications need to be accomplished for the approval in aviation. For this approval the development assurance needs to be fulfilled [6]. Several sensor-less control methods for electrical machines exist in literature [7]-[9], but they are mostly running on a processor, which prevents an approval in aviation. This paper presents a way to implement a sensor-less hysteresis current controller [10] on a Field Programmable Gate Array (FPGA), including the initialization of the controller. The permanently in parallel running initialization achieves an instantaneous switching from field oriented control [11] to hysteresis current control in case of an encoder failure, leading to a higher redundancy of the system. The hysteresis current controller is only used in case of a failure and therefore a start-up from standstill is never required.

\section{IMPLEMENTATION}

\section{A. Working Principle}

The hysteresis controller compares the measured current with a predefined current reference in each phase of the stator winding

$$
\Delta i=i_{\text {ref }}-i_{\text {meas }},
$$

where $\Delta i$ denotes the current difference, $i_{\text {ref }}$ the reference current and $i_{\text {meas }}$ the measured current. We apply sinusoidal current references, shifted by $120^{\circ}$ electrical to each other. Fig. 1 shows the working principle for one phase. If the current difference is greater than $h$, the output of the controller is set to state $S=1$, where $h$ denotes a fixed preset value and describes half of the width of the hysteresis band. If the current difference is smaller than $-h$, the output state is set to $S=0$. The upper switch of the inverter phase leg is turned on for $S=1$ and the lower switch is turned on for $S=0$. The switching status of the upper and lower switch is always complementary. If the current difference is in between the hysteresis band, the previously assumed state is held. We apply this working principle for all three phases and transforming it in the complex plane leads to Fig. 2. The hysteresis current 


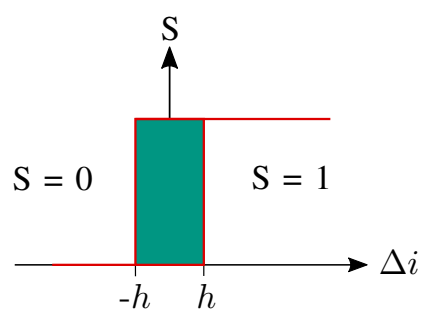

Fig. 1: Working principle of the hysteresis current controller shown for one phase.

controller tries to hold the current deviation vector in the marked area. This would be possible for an infinitely high switching frequency or an induced motor voltage close to zero, $u_{\mathrm{i}} \approx 0 \mathrm{~V}$. For medium or high induced voltages of the motor and a finite switching frequency this is not possible. This is due to the fact that the change of the converter's output current is only determined by the induced voltage of the motor for a freewheeling of the converter. Therefore, the current deviation for one phase can also be in the range of $[h, 2 h]$ and $[-h,-2 h]$, depending on the operating point. This corresponds to the area of the triangles in the complex plane for the current deviation vector. It can be seen from Fig. 2 that it is not possible to actively control a freewheeling state $(1,1,1)$ or $(0,0,0)$.

\section{B. Initialization}

We measure the current continuously to initialize the hysteresis current controller in case of a healthy encoder. Using the information of the phase currents, we can compute the actual phase angle $\phi_{0}$ of the current vector for phase a. In case of a failure, the computed phase angle is hold and incremented accordingly to the reference rotor speed. The reference rotor speed equals the most recently measured rotor speed. We multiply the measured current amplitude by a security factor $k>1$ to stabilize the controller. Therefore, the amplitude of

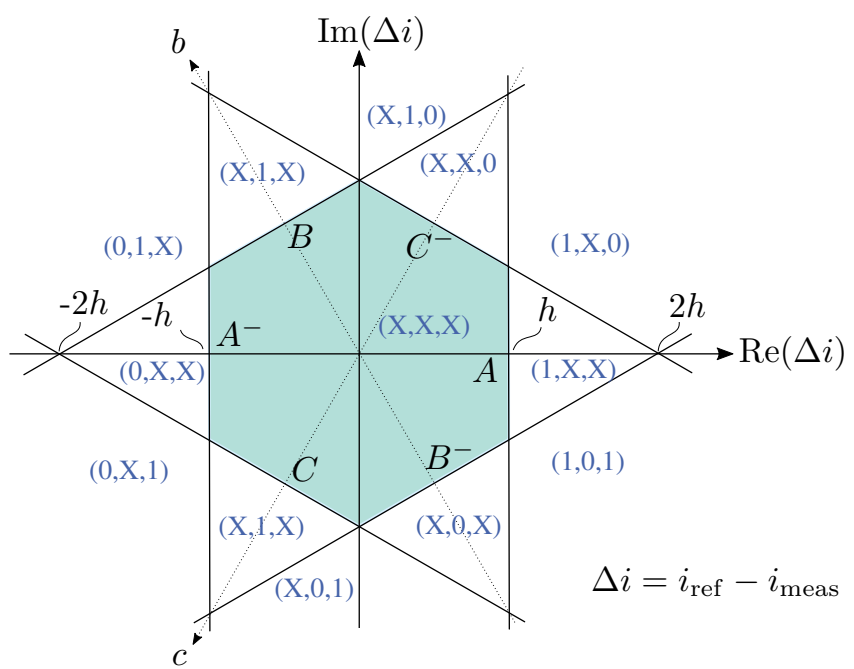

Fig. 2: Working principle of the hysteresis current controller shown for all three phases in the complex plane. the reference current is given by

$$
i_{\mathrm{s}}=k \sqrt{i_{\mathrm{d}}^{2}+i_{\mathrm{q}}^{2}},
$$

where $i_{\mathrm{s}}$ denotes the current reference amplitude, $i_{\mathrm{d}}$ the current component of the machine on the direct axis and $i_{\mathrm{q}}$ the current component on the quadrature axis. Each phase is shifted by $120^{\circ}$ electrically, leading to the current references

$$
i_{\mathrm{ref},(\mathrm{a}, \mathrm{b}, \mathrm{c})}=i_{\mathrm{s}} \sin \left(\omega_{\mathrm{syn}} t+\phi_{0}+\phi\right),
$$

where $\phi=\left(0,-\frac{2 \pi}{3}, \frac{2 \pi}{3}\right)$ and $\omega_{\mathrm{syn}}$ describes the synchronous rotor angular velocity right before switching.

\section{Analytical Model}

We describe the dynamics caused by the switching action in an analytical model. The angles we are using in the following section are graphically explained in Fig. 3. We assume that the current amplitude is increased by a factor of $k-1$ at the switching moment. The initial pilot angle $\theta_{0}$, which defines the angle between the stator current vector in the dq-plane and the d-axis, used for field-oriented control in case of a healthy encoder is given by

$$
\theta_{0}=\frac{\pi}{2}-\arctan \left(\frac{i_{\mathrm{d}}}{i_{\mathrm{q}}}\right)
$$

and is assumed not to change at the switching moment. We assume phase currents with a constant amplitude, which implies operating points on a circle in the dq-plane. Based on measured flux linkages, the inner torque of the machine can be computed by

$$
T_{\mathrm{i}}=\frac{3}{2} p\left(\Psi_{\mathrm{d}} i_{\mathrm{q}}-\Psi_{\mathrm{q}} i_{\mathrm{d}}\right) .
$$

Therein $p$ denotes the number of pole pairs, $\Psi_{\mathrm{d}}$ the flux linkage on the direct axis and $\Psi_{\mathrm{q}}$ the flux linkage on the quadrature axis. The dynamics excited by the additional current amplitude at the switching moment can be described by (5). At the moment of switching action, the current amplitude is increased by $k-1$ and therefore leading to an accelerating torque. To describe this torque, we assume to have a magnetic linear machine. The accelerating torque is calculated by

$$
\begin{aligned}
T_{\mathrm{a}}= & \frac{3}{2} p\left[\left(\Psi_{\mathrm{PM}} k i_{\mathrm{q}}+\left(L_{\mathrm{d}}-L_{\mathrm{q}}\right) k^{2} i_{\mathrm{d}} i_{\mathrm{q}}\right)\right. \\
& \left.-\left(\Psi_{\mathrm{PM}} i_{\mathrm{q}}+\left(L_{\mathrm{d}}-L_{\mathrm{q}}\right) i_{\mathrm{d}} i_{\mathrm{q}}\right)\right] .
\end{aligned}
$$

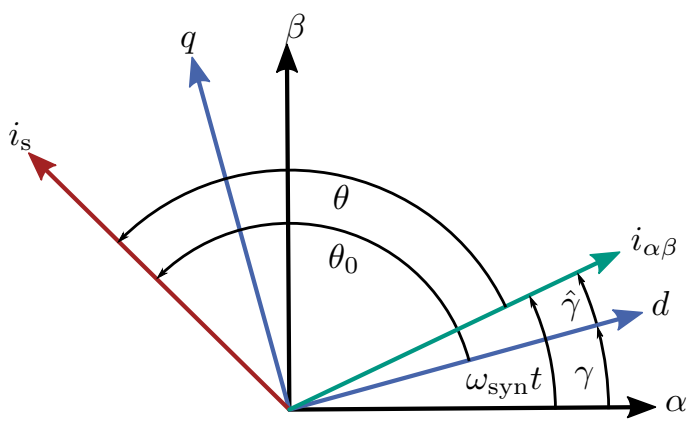

Fig. 3: Graphical explanation of used angles. 
Therein denotes $\Psi_{\mathrm{PM}}$ the permanent magnet flux linkage and $L_{\mathrm{d}}$ along with $L_{\mathrm{q}}$ the inductance in d- and q-direction, respectively. Expressing the d- and q-current components with its current amplitude $i_{\mathrm{s}}$ and the pilot angle $\theta$

$$
i_{\mathrm{d}}=i_{\mathrm{s}} \cos (\theta), \quad i_{\mathrm{q}}=i_{\mathrm{s}} \sin (\theta)
$$

leads to the following first-order non-linear differential equation

$$
\begin{aligned}
J \dot{\hat{\omega}}= & \frac{3}{2} p\left[\Psi_{\mathrm{PM}} i_{\mathrm{s}} \sin (\theta)(k-1)\right. \\
& \left.+\left(L_{\mathrm{d}}-L_{\mathrm{q}}\right) i_{\mathrm{s}}^{2} \sin (\theta) \cos (\theta)\left(k^{2}-1\right)\right]-b \hat{\omega}
\end{aligned}
$$

where $J$ describes the moment of inertia of the system, $\hat{\omega}$ the additional angular velocity caused by the switching action and $b$ the friction coefficient. Using the link between the pilot angle $\theta$ and super positioned rotor angle $\hat{\gamma}$, defined by the angle between the rotor angle $\gamma$ and the angle of the stator current vector in the complex plane $\omega_{\text {syn }} t$, caused by the switching action

$$
\hat{\gamma}=\theta_{0}-\theta
$$

we can solve the differential equation. The solution is a damped oscillation given by

$$
\begin{aligned}
\hat{\gamma}(t)= & -\frac{b}{2 J} \cdot e^{-\left(\frac{b}{2 J}\right) t} \cdot B \cdot \cos (a t)-\frac{\Psi_{\mathrm{PM}}}{\left(L_{\mathrm{d}}-L_{\mathrm{q}}\right) i_{\mathrm{s}}(k+1)} \\
& -\arctan \left(\frac{i_{\mathrm{d}}(t=0)}{i_{\mathrm{q}}(t=0)}\right),
\end{aligned}
$$

where $a=\sqrt{\left(\frac{b}{2 J}\right)^{2}+\frac{3 p\left(L_{\mathrm{q}}-L_{\mathrm{d}}\right)\left(k^{2}-1\right)}{2 J}} i_{\mathrm{s}}$ and

$B=-\frac{\Psi_{\mathrm{PM}}}{\left(L_{\mathrm{d}}-L_{\mathrm{q}}\right) i_{\mathrm{s}}(k+1)}-\arctan \left(\frac{i_{\mathrm{d}}(t=0)}{i_{\mathrm{q}}(t=0)}\right)$.

For highly saturated machines these equations do not hold. To get the impact of saturation the current dependency of the inductances need to be taken into account. Using current dependent inductances, the linear differential equation can not be solved the way it is shown here. Therefore, a numerical solver is used to solve the differential equation

$$
J \dot{\hat{\omega}}=f\left(i_{\mathrm{s}}, \theta\right)-T_{\mathrm{L}}-T_{\mathrm{D}}(\hat{\omega}),
$$

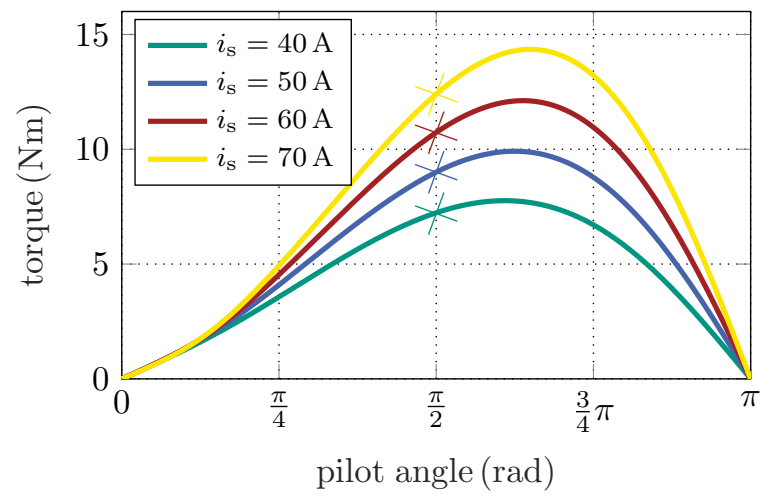

Fig. 4: Inner torque of the machine as a function of the pilot angle $\theta$ for various current amplitudes from $i_{\mathrm{s}}=40 \mathrm{~A}$ up to $i_{\mathrm{s}}=70 \mathrm{~A}$ and exemplary stable operating points marked with crosses. where $f\left(i_{\mathrm{s}}, \theta\right)$ denotes the inner torque of the machine as a function of the current amplitude and the pilot angle. $T_{\mathrm{D}}(\hat{\omega})$ denotes the additional damping torque caused by the excited oscillation. The load torque $T_{\mathrm{L}}$ is assumed to be constant. The inner torque functions of the machine for changing current amplitudes from $i_{\mathrm{s}}=40 \mathrm{~A}$ up to $i_{\mathrm{s}}=70 \mathrm{~A}$ are shown in Fig. 4 with exemplary stable operating points marked with crosses.

\section{RESULTS}

The simulation results are obtained in the MATLAB Simulink environment and the electrical machine was implemented in Simscape to use the advantage of an acausal simulation. For simulation and measurement the machine is operated at a rotor speed of $3000 \mathrm{rpm}$, a DC link voltage of $300 \mathrm{~V}$ and an applied load torque of $8.2 \mathrm{Nm}$. The upper switching frequency limit of the three-phase inverter is set to $20 \mathrm{kHz}$. The number of pole pairs is $p=3$ and the stator phase inductance of the machine is given by $L_{\mathrm{d}}=186 \mu \mathrm{H}$ and $L_{\mathrm{q}}=273 \mu \mathrm{H}$. The machine parameters are summarized in Table I.

\section{A. Switching Action}

At $t=0 \mathrm{~s}$ an encoder failure occurs and the control switches from field oriented control to the hysteresis current control with a security factor of $k=1.2$. Fig. 5a and Fig. 5b show the results in the dq-plane for simulation and measurement. The healthy machine is operated at the Maximum Torque Per Ampere (MTPA) point [12], [13], which is given by $i_{\mathrm{q}}=40 \mathrm{~A}$ and $i_{\mathrm{d}}=-15 \mathrm{~A}$ at nominal load torque. After switching, the stationary point settles to $i_{\mathrm{q}}=51 \mathrm{~A}$ and $i_{\mathrm{d}}=6 \mathrm{~A}$, which is equal to the intersection of the constant torque hyperbola corresponding to the load torque of $8.2 \mathrm{Nm}$ and the constant stator current circle corresponding to the current reference amplitude of $51.3 \mathrm{~A}$. There is a maximum difference of $6 \%$ of the stator current amplitude between simulation and measurement. This is caused by the assumption of a constant air gap length and the extrapolation error of the measured saturation effects used in the simulation. The switching entails an instantaneous rise of the inner torque of the machine, which causes an additional sinusoidal oscillation of the rotor speed. This oscillation was described analytically in section II-C.

TABLE I

Machine and Simulation Parameters

\begin{tabular}{cc}
\hline Parameters & Values \\
\hline Inductance in d-axis & $186 \mu \mathrm{H}$ \\
Inductance in q-axis & $273 \mu \mathrm{H}$ \\
Number of pole pairs & 3 \\
Moment of inertia & $8.5 \cdot 10^{-4} \mathrm{kgm}^{2}$ \\
Nominal rotor speed & $3000 \mathrm{rpm}$ \\
Nominal load torque & $8.2 \mathrm{Nm}$ \\
DC link voltage & $300 \mathrm{~V}$ \\
Rated current & $100 \mathrm{~A}$ \\
Switching frequency & $20 \mathrm{kHz}$ \\
\hline
\end{tabular}




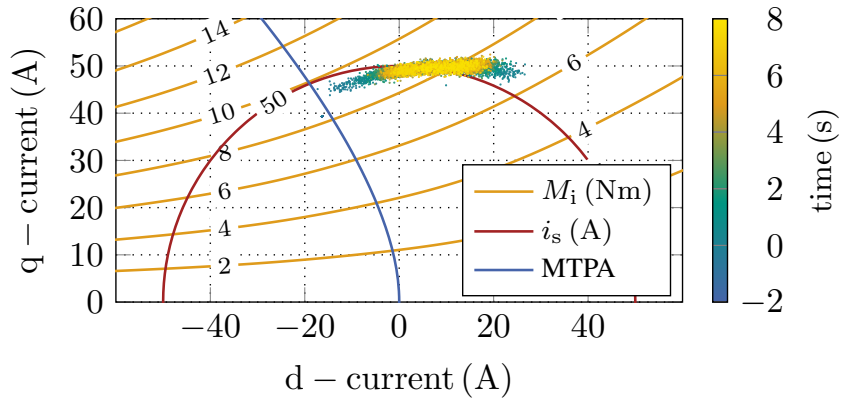

(a) Simulation

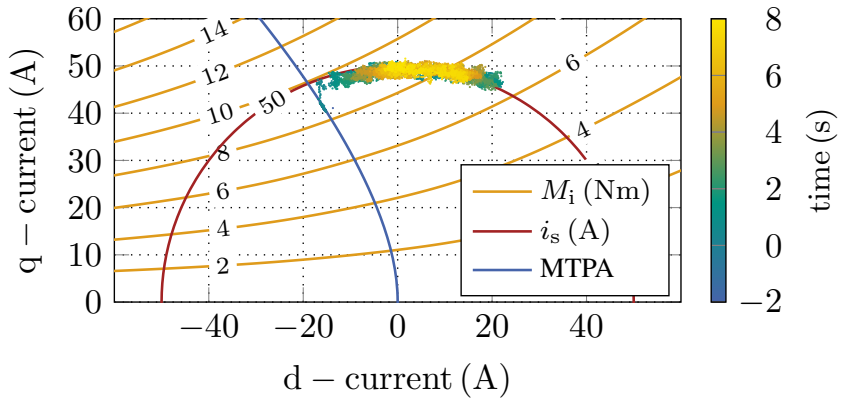

(b) Measurement

Fig. 5: Comparison of simulation and measurement results of the switching action in the dq-plane. Initial current amplitude is set to $42.5 \mathrm{~A}$, security factor is 1.2 , rotor speed is $3000 \mathrm{rpm}$ and load torque is $8.2 \mathrm{Nm}$.

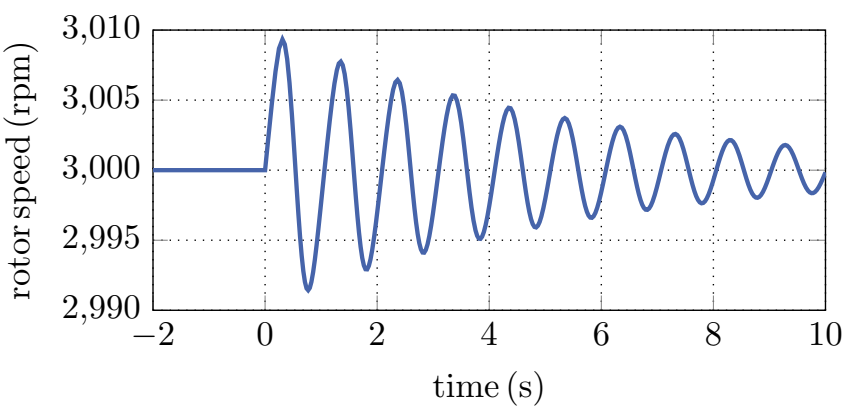

(a) Rotor speed

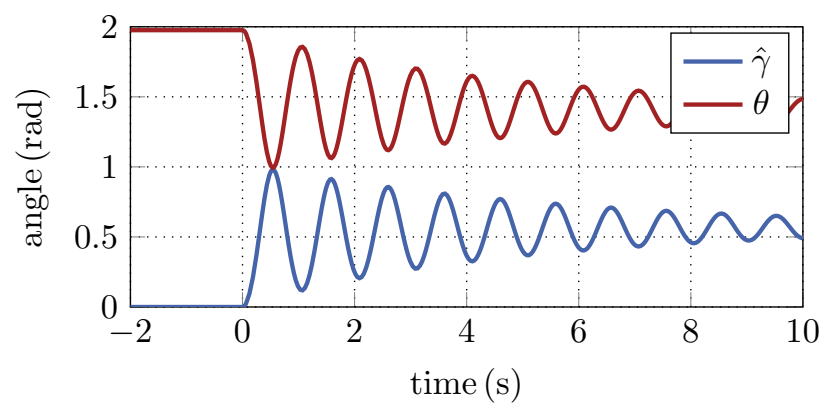

(b) Super positioned rotor angle and pilot angle

Fig. 6: Response in time domain caused by the switching action at $t=0 \mathrm{~s}$ for (a) rotor speed and (b) super positioned rotor angle and pilot angle. The initial rotor speed is set to $3000 \mathrm{rpm}$, the load torque to $8.2 \mathrm{Nm}$, the initial current amplitude is $42.5 \mathrm{~A}$ and the security factor is set to 1.2 .

For the given inner machine torque function of Fig. 4, the numerical result is shown in Fig. 6. It can be seen that the motor operates at synchronous speed until $t=0 \mathrm{~s}$, when the encoder failure occurs. The rotor speed is accelerating due to an increased machine torque. Similarly to the rotor speed, the super positioned rotor angle $\hat{\gamma}$ is increasing. This is due to the fact that the hysteresis current controller is still trying to control a current with a frequency equal to the last measured rotor frequency right before switching. At the same time the current operating points are turning clockwise on the constant current circle in the dq-plane. This can be seen in a decreasing pilot angle, which implies a reduced inner torque of the machine. At about $t=0.5 \mathrm{~s}$ the maximum rotor speed is reached and the load torque equals the inner machine torque. At this point the rotor speed starts decreasing, whereas the rotor angle is still increasing until the rotor speed equals synchronous speed is reached. At this point the pilot angle also starts increasing. The oscillation is damped by the friction inside the machine and settles at the intersection point of the constant torque hyperbola and the stator current circle. For further comparison of the shown numerical results with simulation and measurement results, the oscillation amplitude of the rotor speed excited by the switching action and the oscillation frequency, are analysed in detail for a set of security factors. Fig. 7a and Fig. 7b show a comparison of analytical solution, simulation and measurement for the oscillation amplitude and frequency, respectively. For an increasing security factor, the amplitude and frequency of the oscillation are also increasing. The amplitude of the analytical solution deviates from the measurement by a maximum of $14 \%$. The analytically computed frequency deviates from the measurement by $24 \%$ up to $35 \%$ for a security factor of $k=1.2$ up to $k=1.4$. This deviation is caused by the assumption of phase currents with a constant amplitude, which implies operating points on a circle in the dq-plane. The assumption does not hold in simulation and measurement, as there are also oscillations in radial direction of the circle in Fig. 5a and Fig. 5b. In the next sections only measurement results are analysed, as the difference between simulation and measurement is marginal.

\section{B. Change of Load Torque}

In this section the change of the load torque is analysed. Therefore the load torque is linearly increased from $2.2 \mathrm{Nm}$ up to $8.5 \mathrm{Nm}$ in a time range of $6 \mathrm{~s}$. The current reference amplitude is set to $55 \mathrm{~A}$. Fig. 8 shows the result. One can see that the d-and q-current components stay on the constant stator current circle, turning counter clockwise. The machine still runs stable as an increase of the pilot angle leads to an increase of the inner machine torque. The motor is stable as long as this condition holds. The critical point is the MTPA point, where 


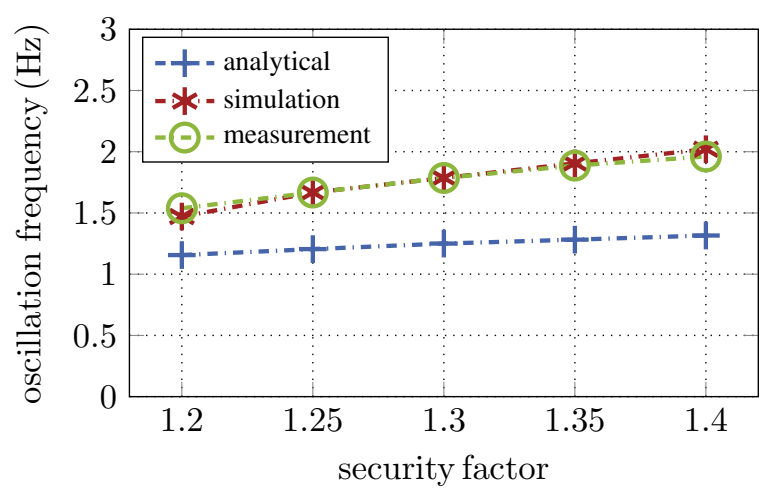

(a) Oscillation amplitude

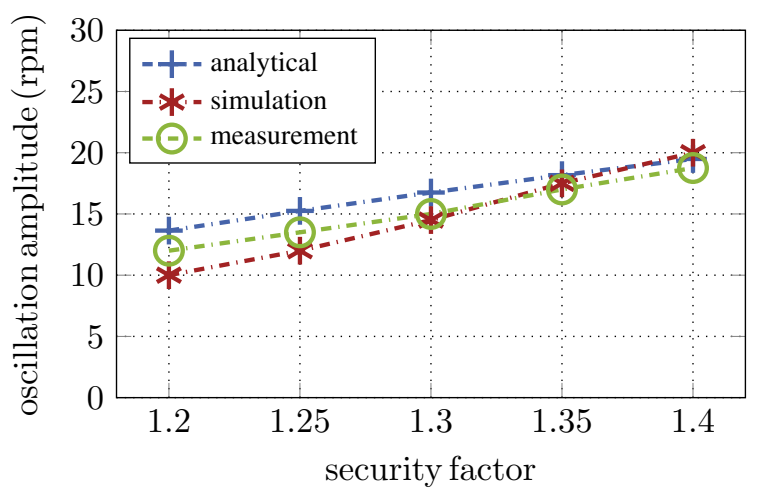

(b) Oscillation frequency

Fig. 7: Comparison of analytical solution, simulation and measurement results of the excited oscillation frequency due to switching action at a rotor speed of $3000 \mathrm{rpm}$, a current amplitude of $42.5 \mathrm{~A}$, a load torque of $8.2 \mathrm{Nm}$ and a varying security factor of $k=1.2$ up to $k=1.4$ in steps of 0.05 .

the maximum torque per ampere is produced. If the pilot angle is further increased the machine gets unstable, because the inner machine torque is decreasing with an increasing pilot angle. Due to the current harmonics, caused by the operating principle of the hysteresis current controller, it can be seen that the security factor is necessary. The security factor provides a margin to the stability limit and prevents the stator current passing the critical point, leading to an unstable machine operation.

\section{Change of Current Amplitude}

To further analyse the hysteresis current controller, the influence of a changing current amplitude is measured. The initial current amplitude is set to $50 \mathrm{~A}$ and increases up to $70 \mathrm{~A}$ in a time range of $2 \mathrm{~s}$. The rotor speed is given by $3000 \mathrm{rpm}$ and the load torque is $8.2 \mathrm{Nm}$. The results can be seen in Fig. 9. It is shown that the dq-current components oscillate in parallel direction of the stator current circle following the constant torque hyperbola, until they reach the constant stator current circle corresponding to $70 \mathrm{~A}$. The current oscillations can be explained by the same way as it was described for the switching action. The stator current continuously increases, leading to a higher inner machine torque. Thus the rotor

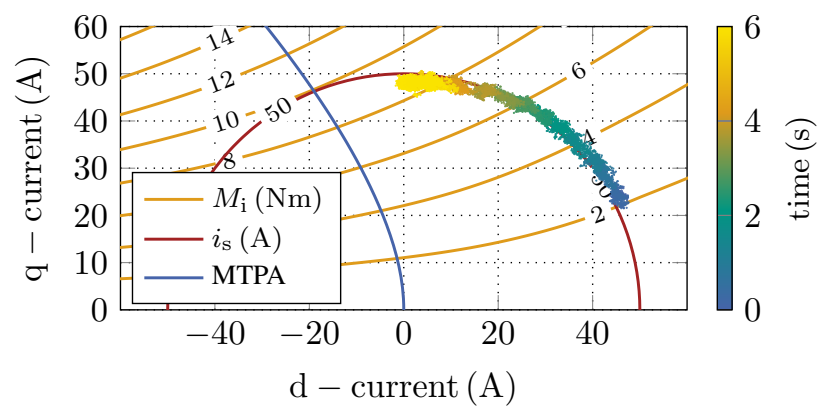

Fig. 8: Current components in dq-plane with a load torque increase from $2.2 \mathrm{Nm}$ up to $8.5 \mathrm{Nm}$ in a time range of $6 \mathrm{~s}$ with a current reference amplitude of $55 \mathrm{~A}$. speed also increases. This leads to a changing pilot angle and therefore to oscillating dq-current components. Increasing the reference current amplitude leads to an increased stability of the machine. A higher torque can be produced with the given current amplitude, which increases the margin to the critical point. The critical point is given by the intersection of the constant torque hyperbola and constant stator current circle with a pilot angle bigger or equal to the pilot angle of the MTPA point corresponding to the load torque. In addition to a bigger margin to the critical point, a more robust operation is reached in this case. A higher $\frac{\mathrm{d} T_{\mathrm{i}}}{\mathrm{d} \theta}$ leads to a more robust operation as the change in pilot angle for a given load disturbance is smaller leading to smaller oscillations in the dq-current components. The response of the hysteresis current controller is faster under the assumption of a constant electric time constant. In the starting point, the torque slope is given by $5 \frac{\mathrm{Nm}}{\mathrm{rad}}$, whereas it is increased by $100 \%$ reaching $10 \frac{\mathrm{Nm}}{\mathrm{rad}}$ in the new operating point. This robustness highly depends on the machine parameters. The higher the difference in $L_{\mathrm{d}}$ and $L_{\mathrm{q}}$ and the higher the saturation level of the machine is, the more robust the operation is. The drawback of a more robust operating point is the efficiency. A higher current is needed to produce the necessary torque leading to a lower efficiency.

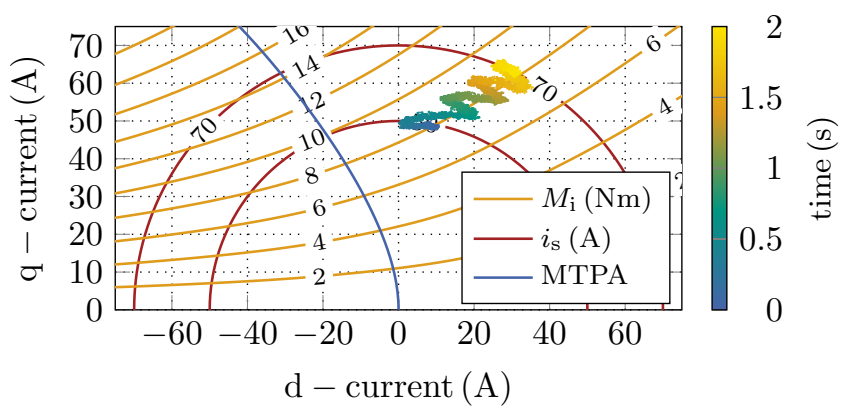

Fig. 9: Current components in dq-plane with a stator current increase from $50 \mathrm{~A}$ up to $70 \mathrm{~A}$ in a time range of $2 \mathrm{~s}$ with a load torque of $8.2 \mathrm{Nm}$. 


\section{Current Harmonics}

Following the current harmonics are analysed. A current reference amplitude of $60 \mathrm{~A}$ is applied at a load torque of $8.2 \mathrm{Nm}$ and a rotor speed of $3000 \mathrm{rpm}$. Fig. 10. shows the result. The harmonics can be clearly seen in the phase currents. The Total Harmonic Distortion (THD) is computed to $29 \%$. This is due to the fact that the hysteresis current controller can not actively set a freewheeling state. This impact is most visible at the peaks of the phase currents, where the current needs to be kept nearly constant. In the range of zerocrossing a high slope of the phase current is required. Under the assumption of a constant induced voltage of the machine the time of the needed freewheeling state is shorter in the range of zero-crossing than around the peaks. As the hysteresis current controller can not actively set a freewheeling state, the harmonics produced by the controller are smaller in the region of zero-crossing. A switching in one phase also causes a change in the phase current of the other two phases. This means there are up to 6 switching actions in one switching period. Due to relatively low inductances the switches are mostly triggered, whenever it is possible and there are mostly 6 switching actions in one switching period. This implies that the most dominant harmonic frequency equals three times the upper switching frequency limit.

\section{CONCLUSION AND FUTURE WORK}

The presented hysteresis current controller was simulated, implemented and successfully validated on the test bench. The controller was implemented on a FPGA, which allows an approval in aviation. Although oscillations are excited at the switching moment, a stable operation of the electrical machine is ensured. The MTPA point is the stability limit for the machine and an operation margin is always needed to stay stable. This is fulfilled by applying a security factor $k>1$. In case of a load increase, the dq-current components turn counter clockwise and clockwise in case of a load decrease. Increasing the current reference amplitude, the dq-current components are following the constant torque hyperbola, until they reach

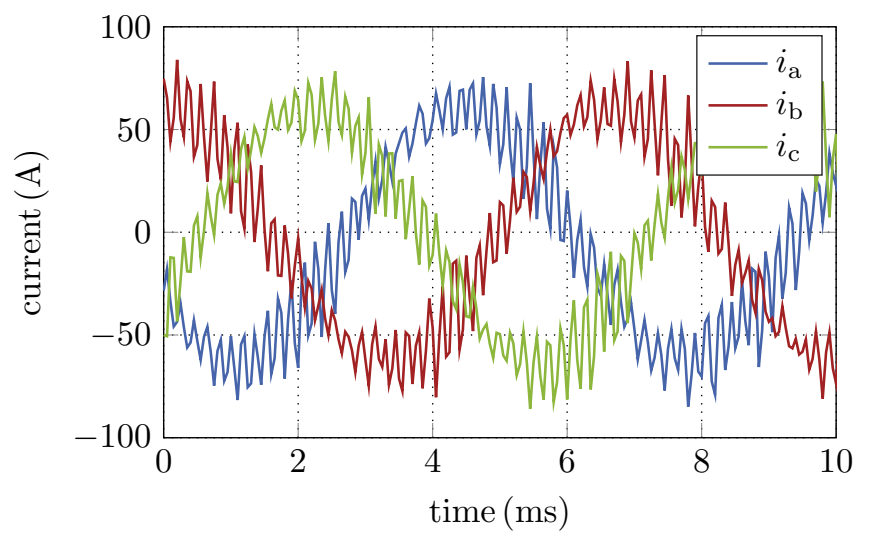

Fig. 10: Current components in dq-plane with a stator current increase from $50 \mathrm{~A}$ up to $70 \mathrm{~A}$ in a time range of $2 \mathrm{~s}$ with a load torque of $8.2 \mathrm{Nm}$. the constant stator current circle corresponding to the set current reference amplitude. Increasing the current reference amplitude gives a more robust operating point, decreasing the efficiency at the same time. Due to the operating principle, the phase currents have a high harmonic portion and the THD was measured to $29 \%$ in a defined operating point. It was shown that the more bend the torque hyperbola the more robust the machine operation is and the faster is the hysteresis current controller response.

In the future work, a multilayer hysteresis band should be implemented to give the opportunity of actively setting a freewheeling state of the converter, to significantly reduce the current harmonics. In addition to that, the dynamics need to be analysed in-depth, especially for a change in rotor speed. At a last point, a predictive controller should be implemented, which computes the current slopes and therefore estimates the best switching moment. This might not be directly after leaving the hysteresis band in one phase.

\section{REFERENCES}

[1] A. Boglietti, A. Cavagnino, A. Tenconi, S. Vaschetto, and P. Di Torino, "The safety critical electric machines and drives in the more electric aircraft: A survey," in 35th Annual Conference of IEEE Industrial Electronics, 2009. Piscataway, NJ: IEEE, 2009, pp. 2587-2594.

[2] S. Morimoto, M. Sanada, and Y. Takeda, "Wide-speed operation of interior permanent magnet synchronous motors with high-performance current regulator," IEEE Transactions on Industry Applications, vol. 30, no. 4, pp. 920-926, 1994.

[3] J. Richter and M. Doppelbauer, "Predictive trajectory control of permanent-magnet synchronous machines with nonlinear magnetics," IEEE Transactions on Industrial Electronics, vol. 63, no. 6, pp. 39153924,2016

[4] T. Gemaßmer, J. Richter, M. Schnarrenberger, and M. Braun, "Dynamic overmodulation for highly dynamic current control of ipmsm with saturation characteristics," in SPEEDAM 2014. [Piscataway, N.J.]: IEEE, 2014?, pp. 842-847.

[5] S. Bolognani, L. Tubiana, and M. Zigliotto, "High dynamic pmsm current control by optimal saturation management of current regulators," in IECON'03. [Piscataway, N.J.]: IEEE, 2004, pp. 1261-1266.

[6] I. Clifton A. Ericson, Concise Encyclopedia of System Safety: Definition of Terms and Concepts. Wiley, 2011, ISBN 978-0-470-92975-9.

[7] M. J. Corley and R. D. Lorenz, "Rotor position and velocity estimation for a salient-pole permanent magnet synchronous machine at standstill and high speeds," IEEE Transactions on Industry Applications, vol. 34, no. 4, pp. 784-789, 1998.

[8] H. W. de Kock, M. J. Kamper, and R. M. Kennel, "Anisotropy comparison of reluctance and pm synchronous machines for position sensorless control using hf carrier injection," IEEE Transactions on Power Electronics, vol. 24, no. 8, pp. 1905-1913, 2009.

[9] "An improved position estimator for sensorless control of permanent magnet synchronous motors," vol. 3. EPE'91, 1991, pp. 418-423.

[10] A. Bouzid, P. Sicard, A. Cheriti, and P. K. H. Chaoui, "Adaptive hysteresis current control of active power filters for power quality improvement," in EPEC - 2017 IEEE Electrical Power and Energy Conference.

[11] F. Blaschke, "Das Verfahren der Feldorientierung zur Regelung der Drehfeldmaschine," Dissertation, TU Braunschweig, 1973.

[12] M. Preindl and S. Bolognani, "Model predictive direct torque control with finite control set for pmsm drive systems, part 1: Maximum torque per ampere operation," IEEE Transactions on Industrial Informatics, vol. 9, no. 4, pp. 1912-1921, 2013.

[13] T. Gemaßmer, "Effiziente und dynamische Drehmomenteinprägung in hoch ausgenutzten Synchronmaschinen mit eingebetteten Magneten," Dissertation, Karlsruher Institut für Technologie, 2015. 